\title{
AVALIAÇÃO DAS EMISSÕES GASOSAS DE DIFERENTES TIPOS DE COMBUSTÍVEIS UTILIZADOS E SEUS IMPÁCTOS AMBIENTAIS
}

\author{
Waldir Nagel Schirmer ${ }^{*}$, Andréia Rudniak ${ }^{2}$ \\ 1 - Departamento de Eng. Ambiental da Universidade Estadual do Centro-oeste, Irati-PR, Brasil. \\ 2 - Curso Técnico Florestal, Colégio Florestal Estadual Presidente Costa e Silva, Irati-PR, Brasil.
}

*E-mail: wanasch@yahoo.com.br

Recebido em 05 de julho 2009

Aceito em 31 de julho de 2009

\section{RESUMO}

Este trabalho tem o objetivo de traçar uma revisão sobre os combustíveis utilizados em diferentes processos industriais, com ênfase nos principais gases daí emitidos. A poluição do ar causada por tais poluentes exerce grande influência na saúde humana e em vários ecossistemas, pois diariamente são liberados altas taxas dos mesmos para a atmosfera. Há alguns anos já ocorrem discussões para que haja a minimização dos problemas ambientais, os acordos internacionais estão sendo fundamentais nesse contexto uma vez que, entre metas bem definidas, encontram-se a substituição de combustíveis altamente poluidores. As fontes alternativas de energia têm sido a escolha utilizada pelos países, que além de ambientalmente corretos, possibilitam benefícios para as indústrias.

Palavras-chave: Biocombustível; Emissões gasosas; Indústria; Poluição do ar.

\section{INTRODUÇÃO}

Entende-se como poluição do ar a mudança em sua composição ou em suas propriedades causada por emissões de poluentes (sustâncias em estado sólido, líquido ou gasoso) que, em quantidades elevadas, tornam-no impróprio, nocivo ou inconveniente à saúde do homem, aos animais, vegetais e alguns materiais $[1,2]$.

As emissões existem desde os tempos mais remotos. Sempre os três recursos básicos - ar, água e solo foram capazes de diluir as concentrações aceitáveis de poluentes lançados por processos naturais normais, como das erupções vulcânicas. A era industrial, entretanto, tem contribuído sensivelmente com a redução dessa capacidade de autodepuração do meio ambiente. O uso do carbono estocado durante milhões de anos sob a forma de carvão mineral (combustível pioneiro) e petróleo (consumido em massa a partir do século XX) tem assumido papel de destaque na contribuição dessa poluição. Como conseqüência, diversos estudos científicos revelam os desequilíbrios ecológicos causados pela exploração e uso descontrolado dos recursos naturais que, associados a outros fatores, caracterizam um cenário de poluição sobre os diferentes ecossistemas [1-4].

$\mathrm{O}$ efeito estufa foi identificado no século XIX e, desde então, gases como o $\mathrm{CO}_{2}$, os clorofluorcarbonos (CFC) e o metano $\left(\mathrm{CH}_{4}\right)$ foram relacionados com o constante acréscimo da temperatura terrestre. De 1840 a 1870, a acidificação das precipitações foi reconhecida como um problema da poluição do ar, provocada pelas concentrações de $\mathrm{SO}_{2}$ e $\mathrm{NO}_{\mathrm{x}}$. Na metade do século $\mathrm{XX}$, várias cidades industrializadas do ocidente apresentaram episódios de "smog" (neblina amarelo-amarronzada e de odor desagradável), decorrente da interação química entre os diferentes poluentes do ar (nesse caso, essencialmente hidrocarbonetos e óxidos de nitrogênio) [5,6]. Apesar de problemas ambientais como estes estarem se agravando, o mundo globalizado continuou exigindo uma contínua demanda por energia, fazendo com que a disponibilidade dos recursos naturais chegasse próximo ao limite. Esse fato, aliado a uma nova visão da sociedade sobre o meio ambiente, tem favorecido pesquisas em busca de combustíveis alternativos, menos poluidores. A sociedade atual pressiona para que medidas que evitem problemas ambientais sejam tomadas, afim de evitar que fenômenos como o efeito estufa se agravem.

O primeiro grande encontro mundial para debater o clima foi a Conferência das Nações Unidas sobre Meio Ambiente e Desenvolvimento, a ECO 92, que aconteceu no Rio de Janeiro em 1992, reunindo 178 países. Em 1997, em Quioto, no Japão, foi redigido o Protocolo de Quioto, onde 160 países alcançaram um acordo internacional que tem como objetivo principal a redução das emissões de gás carbônico em 5,2\%, em relação aos níveis de 1990, pelos países desenvolvidos entre o período de 2008 a 2012 [7]. Os países que mais emitem $\mathrm{CO}_{2}$ são os Estados Unidos e a China, respectivamente com $24 \%$ e $15 \%$ das emissões [8].

A má qualidade do ar é bem mais visível nas grandes cidades, com destaque para aquelas localizadas em países em desenvolvimento. As indústrias de base, como refinarias petrolíferas e petroquímicas, metalurgia, indústria alimentícia, de papel e celulose e a de cimento, são normalmente as mais representativas em termos de liberação de gases tóxicos [1,5].

Uma das formas de minimizar a emissão de poluentes, reduzindo impactos ambientais e cumprindo os acordos internacionais, é a substituição gradual de combustíveis fósseis, com alto de carbono, por outros 
combustíveis com baixo ou nenhum teor de carbono (como o hidrogênio). Essa revisão objetiva relacionar os principais contaminantes atmosféricos com seus respectivos combustíveis, seus efeitos à saúde humana e ao meio ambiente, bem como discutir os prováveis substitutos da atual matriz energética, baseada essencialmente no petróleo.

\section{PROCESSOS INDUSTRIAIS $\times$ POLUIÇÃO DO AR}

Segundo Baird [6], “quando um país subdesenvolvido inicia o seu desenvolvimento industrial, sua qualidade do ar piora significativamente".

Atualmente, as indústrias emissoras de poluentes atmosféricos podem ser classificadas de acordo com a natureza do produto gerado. Entretanto, em estudos sobre poluição atmosférica, uma classificação baseada no tipo de matéria-prima é mais adequada. Para Branco e Murgel [1], os poluentes em geral (particulados ou gasosos) podem provir, em geral: da matéria-prima empregada; do combustível utilizado; de subprodutos derivados de reações características do processamento; do próprio produto. É importante ainda ressaltar que muitos compostos poluentes são originados na própria atmosfera (compostos secundários) resultantes da reação entre compostos primários (lançados originalmente no ar).

\section{COMBUSTÍVEIS INDUSTRIAIS}

\subsection{Carvão mineral}

O carvão mineral é um combustível fóssil sólido, usado em grande escala na metade do século XVIII e por um século fez história juntamente com as máquinas a vapor em aplicações estacionárias, até ser substituído parcialmente pelo petróleo, gás natural e energia nuclear. Apesar disso, tem-se mantido numa posição de destaque na matriz energética mundial [9].

Conforme Monteiro et al [10], “o carvão mineral é constituído principalmente por carbono, oxigênio e hidrogênio e se classifica geralmente em quatro tipos: a turfa (com cerca de $60 \%$ de carbono), o linhito $(70 \%)$, a hulha ou carvão betuminoso (80 a $85 \%$ ) e o antracito (90\%)". Pode ainda ser qualificado segundo seu teor de enxofre e cinzas. O carvão brasileiro possui um alto teor de impurezas, as cinzas geralmente ficam entre 40 e $50 \%$ e o enxofre entre 1 e $2,5 \%$; possui ainda um baixo poder calorífico, normalmente entre 3,0 e 4,5 Kcal g ${ }^{-1}$. Atualmente, sua principal utilização compreende as usinas termelétricas, o restante é destinado para a siderurgia e metalurgia.

Nos últimos anos, o carvão mineral tem enfrentado alguma resistência por parte de organismos ambientais. Afinal de contas, durante sua extração, solo e relevo ficam bastante comprometidos, sem falar na emissão de poluentes atmosféricos, uma vez que de todos os combustíveis fósseis, o carvão é o que lança no ar a maior quantidade de $\mathrm{CO}_{2}$, além de $\mathrm{NO}_{\mathrm{X}}, \mathrm{SO}_{\mathrm{X}}$, particulados (sob a forma de cinzas leves e pesadas) e HPA (hidrocarbonetos poliaromáticos) [914].

\section{2 Óleo diesel}

O diesel é um combustível derivado do petróleo, constituído basicamente por hidrocarbonetos alifáticos contendo de 9 a 28 átomos de carbono na cadeia, e em baixas concentrações por enxofre, nitrogênio e oxigênio (com destaque para o teor de enxofre que varia de 0,1 a $1 \%$ ). É um produto inflamável, medianamente tóxico e com odor forte e característico [3].

A popularidade do óleo diesel se deve à sua eficiência, relacionada a um preço inferior em relação a outros combustíveis. É utilizado em aplicações estacionárias (geradores elétricos, máquinas em geral, por exemplo) e móveis (ônibus, caminhões, tratores e pequenas embarcações marítimas e navios) [3].

Em relação à emissão de gases, os principais são o monóxido de carbono (CO), os hidrocarbonetos (HC), óxidos de enxofre $\left(\mathrm{SO}_{\mathrm{X}}\right)$, óxidos de nitrogênio $\left(\mathrm{NO}_{\mathrm{X}}\right)$ e material particulado (MP), com destaque para estes dois últimos. Graças à constante pressão das agências ambientais, no Brasil, o teor de enxofre no diesel baixou de 1 para $0,2 \%$ nas áreas metropolitanas, e finalmente a prática da substituição do diesel e do carvão mineral por outros combustíveis mais limpos estão ajudando no controle das emissões destes poluentes $[3,10,15,16]$.

\subsection{Gás natural}

Foi a partir da década de 70 que o gás natural passou a ser usado como combustível alternativo dos derivados do petróleo e, por apresentar qualidades excepcionais e várias vantagens, hoje é considerado um combustível nobre. O gás natural é um combustível fóssil encontrado acumulado em rochas porosas no subsolo em terra ou mar, podendo estar freqüentemente acompanhado por petróleo (gás associado) ou não. Quimicamente é definido como um mistura de hidrocarbonetos leves, que na temperatura ambiente e pressão atmosférica permanece em estado gasoso. Sua composição pode variar dependendo da origem geológica ou de ter sido ou não processado em unidades industriais. Sua composição básica inclui o metano $\left(\mathrm{CH}_{4}\right)$, que é seu principal componente (aproximadamente $90 \%)$, o etano $\left(\mathrm{C}_{2} \mathrm{H}_{6}\right)$, propano $\left(\mathrm{C}_{3} \mathrm{H}_{8}\right)$, butano $\left(\mathrm{C}_{4} \mathrm{H}_{10}\right)$ e outros mais pesados. $\mathrm{O}$ gás natural não possui cheiro e, por ser mais leve que o ar, dissipa-se com facilidade na atmosfera em caso de vazamento, praticamente eliminando o risco de explosões; todavia, ele é odorizado (com um gás traçador) para que seja detectado $[9,17,18]$.

$\mathrm{Na}$ indústria, o gás natural é utilizado como combustível em vários setores como o metalúrgico, de plástico, cerâmico, de vidros, farmacêutico, têxtil, de borrachas e pneus, de papel e celulose, e como redutor siderúrgico. Outro uso para o gás natural é como matériaprima do setor petroquímico e na produção de fertilizantes. Trata-se de um excelente combustível, visto que apresenta boas condições de controlabilidade e um alto poder calorífico (aproximadamente $15 \mathrm{Kcal} \mathrm{g}^{-1}$ ), sendo ideal em processos que exigem contato direto com o produto final, garantindo a qualidade de acabamento $[9,19,20]$.

Finalmente, o gás natural colabora na preservação da qualidade do ar, por apresentar baixos índices de emissão de poluentes na atmosfera (dentre os combustíveis fósseis é 
o que apresenta a mais baixa emissão de $\mathrm{CO}_{2}$, porém destacam-se as emissões de óxidos de nitrogênio). Como a atenção mundial está cada vez mais voltada para defesa do meio ambiente, o gás natural representa uma das alternativas mais adequadas e disponíveis no século XXI para substituir qualquer fonte de energia convencional $[19,21]$.

\subsection{Biomassa}

Biomassa pode ser definida, de forma simples, como uma fonte de energia limpa (não poluente) e renovável que está sendo usada em contraposição às fontes fósseis. A biomassa está disponível em grande abundância e é derivada de materiais de origem animal, vegetal, industrial e florestal. Tal energia pode ser convertida sob a forma de eletricidade, combustível ou calor. Grande parte dos países, desenvolvidos ou não, está promovendo ações para que as energias alternativas providas de biomassa tenham participação significativa em suas matrizes energéticas [22].

A cana-de-açúcar utilizada para a produção do etanol é a maior fonte de energia renovável do Brasil, com $18 \%$ de participação na matriz energética atual [23], considerando-se o álcool combustível e a cogeração de eletricidade, a partir do bagaço da mesma. Outro exemplo é a queima dos resíduos produzidos pelas indústrias de madeira, como o cavaco e a serragem, que cogeram energia para a própria empresa. Segundo BEN [23], apenas uma pequena parcela de madeira é utilizada para geração de eletricidade, seus principais usos ainda estão na produção de carvão vegetal e nas residências para a cocção e aquecimento. Nesse caso, os briquetes, produzidos a partir da moagem e prensagem de sobras de madeira, serragens e de sub-produtos como casca de coco, bagaço de cana, casca de amendoim, etc., estão sendo uma alternativa bastante utilizada em caldeiras, fornalhas e aquecedores [24].

Atualmente, $13 \%$ da energia produzida no mundo é proveniente de fontes renováveis, nos próximos 30 anos, elas corresponderão a $30 \%$ da energia consumida pela humanidade. Sem dúvida, as principais razões para o aumento na demanda da biomassa são as necessidades de redução do uso de derivados do petróleo e gases poluentes (como os relacionados ao efeito estufa) [22].

\section{PRINCIPAIS POLUENTES EMITIDOS POR FONTES INDUSTRIAIS}

\subsection{Material particulado}

Classe de poluentes constituída de poeiras, neblina, aerossóis, fumaça, fuligem e todo tipo de material sólido ou líquido (à exceção da água pura) que se encontram suspensos no ar devido a suas dimensões microscópicas ou submicroscópicas [5,11].

As fontes emissoras que dão origem a esses poluentes são as mais variadas possíveis. Entre as naturais, a mais elementar fonte de material particulado é a simples suspensão de poeira por ação do vento ou do tráfego de veículos em vias não pavimentadas, bem como o pólen das flores, aerossol marinho e vulcões. Para as emissões de origem antropogênica, destacam-se os veículos especialmente os movidos à diesel - que emitem a agressiva e incômoda fumaça negra, as usinas térmicas à carvão, as queimadas e os processos de incineração em geral $[1,11]$.

\subsection{Compostos sulfurados}

Os compostos sulforosos (que contêm enxofre em sua composição) encontram-se na atmosfera nas seguintes formas: $\mathrm{SO}_{2}$ (dióxido de enxofre), $\mathrm{SO}_{3}$ (trióxido de enxofre), $\mathrm{SO}_{4}{ }^{2-}$ (sulfatos), $\mathrm{H}_{2} \mathrm{~S}$ (sulfeto de hitrogênio), entre outros. $\mathrm{O}$ $\mathrm{SO}_{2}$ é um gás incolor com odor forte, semelhante ao produzido pela queima de palitos de fósforo, e altamente solúvel em água. Grande parte de sua emissão natural dá-se por vulcões, pela degradação biológica e pelos oceanos. A principal fonte antrópica de $\mathrm{SO}_{2}$ é a queima de combustíveis fósseis, sobretudo o carvão, bastante utilizado como combustível. Sabe-se que, por oxidação, o $\mathrm{SO}_{2}$ pode transformar-se em $\mathrm{SO}_{3}$ e este, por sua vez, com a umidade atmosférica origina $\mathrm{o} \quad \mathrm{H}_{2} \mathrm{SO}_{4}$ (ácido sulfúrico), um dos responsáveis pela chuva ácida. $\mathrm{O}_{2} \mathrm{~S}$ é altamente tóxico e com odor característico de ovo podre, tem origem na atividade de decomposição de matéria orgânica por processo anaeróbico, vulcões, atividades geotérmicas e em solos ricos em enxofre. Uma vez na atmosfera e em combinação com o ozônio, pode ser oxidado a $\mathrm{SO}_{2}$, constituindo então uma fonte desse poluente $[1,5,11]$.

A indústria de petróleo emite diretamente $\mathrm{SO}_{2}$ e indiretamente $\mathrm{H}_{2} \mathrm{~S}$, principalmente nas etapas de refino do petróleo e purificação do gás natural. $\mathrm{O} \mathrm{H}_{2} \mathrm{~S}$ também é comum nas emissões das indústrias de polpa celulósica e papel e de metais não ferrosos [6].

\subsection{Compostos nitrogenados}

Os compostos nitrogenados $\left(\mathrm{NO}_{\mathrm{x}}\right)$ compreendem o monóxido de nitrogênio (NO), o dióxido de nitrogênio $\left(\mathrm{NO}_{2}\right)$ e o óxido nitroso $\left(\mathrm{N}_{2} \mathrm{O}\right)$.

$\mathrm{O} \mathrm{N}_{2} \mathrm{O}$ é um gás incolor, formado a partir da queima de combustíveis fósseis e fortemente relacionado ao efeito estufa. Os óxidos de nitrogênio $\left(\mathrm{NO}\right.$ e $\left.\mathrm{NO}_{2}\right)$ também são formados pelas reações de queima de combustíveis fósseis e biomassa em altas temperaturas, ou seja, motores de veículos, processos industriais, usinas termelétricas e incinerações. Por efeito do excesso de ar, o NO oxida-se a $\mathrm{NO}_{2}$ que também pode ser convertido, na presença de umidade, a $\mathrm{HNO}_{3}$ (ácido nítrico), um dos precursores da chuva ácida $[1,11]$.

\subsection{Monóxido e dióxido de carbono}

Independentemente do combustível utilizado, o produto final de toda combustão será o $\mathrm{CO}_{2}$ (dióxido de carbono) e vapor de água. $\mathrm{O} \mathrm{CO}_{2}$ é um gás incolor e sem cheiro, considerado não tóxico quando comparado com outros poluentes, até mesmo por ser constituinte natural da atmosfera. Entretanto, se o oxigênio disponível não for suficiente, não ocorrerá a queima completa (o que acontece na maioria das vezes), resultando a formação de $\mathrm{CO}$ (monóxido de carbono), um dos mais tóxicos poluentes. Ambos os gases são encontrados em maiores concentrações em áreas urbanas, devido ao grande consumo de combustíveis, tanto pela indústria como pelos veículos [1,2]. 
Estudo realizado em 2008 pela CETESB (Companhia de Tecnologia de Saneamento Ambiental ligada à Secretaria do Meio Ambiente do governo de São Paulo) aponta que as oito indústrias que mais emitem $\mathrm{CO}_{2}$ no Estado de São Paulo são responsáveis por $63 \%$ de todas as emissões. Baseando-se nesse estudo, conclui-se que os setores petroquímicos, juntamente com a indústria de aço e ferro-gusa e de minerais não metálicos são os maiores emissores de $\mathrm{CO}_{2}$ na atmosfera, um dos gases mais relacionados ao aquecimento global, uma vez que possui alto poder de retenção das radiações emitidas pelo sol [25].

\subsection{Compostos orgânicos voláteis (COV)}

Os compostos orgânicos voláteis (COVs) incluem a maioria dos solventes, lubrificantes e combustíveis em geral, sendo comumente emitidos por indústrias químicas e petroquímicas (fontes fixas) e por veículos automotores (fontes móveis). Considera-se COV todo composto que, à exceção do metano, contém carbono e hidrogênio, os quais possivelmente podem ser substituídos por outros átomos como halogênios, oxigênio, enxofre, nitrogênio ou fósforo, excluindo-se óxidos de carbono e carbonatos. De modo geral, são compostos orgânicos com elevada pressão de vapor (sendo facilmente vaporizados às condições de temperatura e pressão ambientes), apresentando valores da constante da Lei de Henry superiores a $10^{-5} \mathrm{~atm} \mathrm{~m}^{3} \mathrm{~mol}^{-1}$ (ou $\mathrm{K}_{\mathrm{H}}>4,1.10^{-4}$ a $25^{\circ} \mathrm{C}$ ) e com pesos moleculares inferiores a $200 \mathrm{~g} \mathrm{~m} \mathrm{ol}^{-1}$ [26-30].

O conceito mais "utilizado", entretanto, é o da Agência Americana de Proteção Ambiental (USEPA), que definiu COV como toda substância carbonada (exceto monóxido de carbono, dióxido de carbono, ácidos carbônicos, carbonetos, carbonatos metálicos e carbonatos de amônia) que participam de reações fotoquímicas da atmosfera, embora alguns destes compostos voláteis tenham reatividade química negligenciável. Estas definições compõem uma lista considerável de compostos químicos (mais de 600), onde quase um terço destes constitui-se substâncias tóxicas [29-32].

Compostos orgânicos derivados do petróleo constituem um dos maiores problemas de poluição do ar. Dentre eles, encontram-se os BTEX (benzeno, tolueno, etilbenzeno e xilenos); outros compostos menos abundantes mas fortemente reativos incluem o óxido de etileno, o formaldeído, o fenol, o tetracloreto de carbono, os clorofluocarbonados (CFC) e as bifenila policloradas (PCB) [33].

\section{PRINCIPAIS IMPACTOS DOS POLUENTES}

\subsection{Sobre a saúde}

Dentre os efeitos da poluição atmosférica à saúde humana destacam-se "problemas oftálmicos, doenças dermatológicas, gastrintestinais, cardiovasculares e pulmonares, além de alguns tipos de câncer" [34]. Os efeitos causados pelos poluentes dependem de sua concentração na atmosfera, do tempo de exposição do indivíduo e da sensibilidade de cada pessoa [35]. Notadamente, os efeitos são mais sentidos por crianças e idosos, por possuírem baixa resistência. Considera-se que a inalação é a via mais importante e vulnerável; todavia, a contaminação também pode acontecer por indigestão ou contato direto com a pele [36,37].

Na classe dos particulados, as partículas minúsculas (ditas inaláveis), "causam irritação nos olhos e garganta, reduzindo a resistência às infecções e ainda penetram nas regiões mais profundas dos pulmões, provocando doenças crônicas" [11].

Em concentrações baixas, a inalação de dióxido de enxofre provoca espasmos passageiros dos músculos lisos dos bronquíolos musculares. A exposição em concentrações progressivamente maiores está associada ao aumento de problemas respiratórios, podendo aumentar a incidência de rinite, faringite e bronquite, irritação dos olhos nariz e garganta $[1,11]$.

O monóxido de carbono constitui-se num dos compostos mais tóxicos, devido ao fato de não possuir cor, não ter cheiro, não causar irritação e por não ser percebido pelos sentidos, podendo matar por asfixia quando em altas concentrações e em ambientes fechados. A exposição contínua a médias concentrações produz efeitos nocivos no sistema nervoso central, cardiovascular e pulmonar [11].

O dióxido de carbono não causa efeitos diretos à saúde, mas está indiretamente relacionado com o aumento da temperatura terrestre [2].

Os compostos orgânicos voláteis (gases e vapores, geralmente associados a odores desagradáveis) são irritantes dos olhos, nariz, pele e trato respiratório superior. Diversos deles são considerados carcinogênicos (benzeno e HPA estão associados à leucemia) ou mutagênicos (como tolueno e xilenos) quando em exposição prolongada; em elevadas concentrações podem provocar náusea, dores de cabeça, cansaço, letargia e tonturas $[11,30]$.

Os $\mathrm{NO}_{\mathrm{X}}$ levam ao aumento da suscetibilidade às infecções respiratórias como asma e bronquite [11].

\subsection{Sobre o ecossistema}

\section{Efeito estufa}

O efeito estufa é fundamental à manutenção da vida na Terra, sendo um fenômeno natural que ocorre há bilhões de anos e mantém a temperatura média do planeta girando em torno de $15^{\circ} \mathrm{C}$. Isto porque gases como o dióxido de carbono, metano, óxido nitroso, entre outros e o vapor d'água, formam uma camada na atmosfera que aprisiona parte das radiações emitidas pelo sol. Sem esses gases, a Terra seria um ambiente gelado, com temperatura média de $17^{\circ} \mathrm{C}[4,38]$.

Entretanto, nos últimos 150 anos (após a Revolução Industrial) o aumento excessivo desses gases na atmosfera, ocasionada principalmente pela atividade antropogênica (uso de combustíveis fósseis, queimadas, desmatamento, etc.), teve como conseqüência o aumento da retenção de calor, o que potencializou o efeito estufa da Terra. Apenas no último século, o aumento médio da temperatura foi de $0,74^{\circ} \mathrm{C}$, e ainda existem previsões de acréscimos significativos se a emissão dos gases continuar a crescer na taxa atual, o que pode resultar em aumentos de até $5,8^{\circ} \mathrm{C}$ até o fim do século XXI. Além da elevação da temperatura média do planeta, o aquecimento global poderá causar alteração das correntes 
marinhas, dos ventos, no sistema de evaporação das florestas, na elevação do nível do mar, derretimento de geleiras, alteração da biodiversidade, oferta de água e de alimentos, saúde das pessoas e até economia mundial [3839].

As alterações climáticas e a necessidade de redução das emissões de gases causadores do efeito estufa vêm sendo alvo de reuniões internacionais. O Brasil foi o primeiro país a firmar a Convenção das Nações Unidas sobre Mudança do Clima, durante a Rio 92. Em 1997 foi assinado o Protocolo de Quioto, um passo simbolicamente importante nessa trajetória. Mesmo com a união de vários países firmando um compromisso para evitar conseqüências mais graves para o clima, o protocolo demorou muito para ser ratificado, o que só aconteceu em 2005, depois da decisão russa de ratificá-lo.

\section{Chuva ácida}

A acidificação das precipitações foi descoberta no século passado pelo químico inglês Robert Angus Smith, que observou que as concentrações do íon sulfato $\left[\mathrm{SO}_{4}{ }^{2-}\right]$ na chuva eram maiores nos subúrbios (onde havia grandes plantas para queima de carvão) do que nos campos da cidade de Manchester, na Inglaterra. Desde então, o termo chuva ácida vem sendo largamente utilizado no lugar de deposição ácida, uma vez que este último é mais abrangente, pois as "deposições ou precipitações ácidas podem ser na forma de chuva, neve ou até mesmo de materiais sólidos ou gasosos, que apresentem características ácidas" [5].

Normalmente, em seu estado normal de acidez, a chuva apresenta $\mathrm{pH}$ de 5,6, valor estabelecido em razão do dióxido de carbono $\left(\mathrm{CO}_{2}\right)$ já presente na atmosfera. A chuva só é considerada ácida quando apresenta valores de $\mathrm{pH}$ inferiores a 5,6, aí sim causado pela presença de compostos sulfurados e nitrogenados decorrentes de emissões antrópicas [5].

Um dos problemas da chuva ácida é o fato de ela ser transportada através de grandes distâncias, podendo vir a cair em locais onde não há queima de combustíveis fósseis. Das conseqüências acarretadas por sua acidez, estão a diminuição do $\mathrm{pH}$ das águas (redução da população de peixes), modificação da fauna e da flora, alteração na química dos solos, prejuízo com a agricultura e danos no crescimento das árvores (corrosão das folhas), corrosão de monumentos, prédios históricos, esculturas e outros objetos culturais importantes [35].

\section{Smog fotoquímico}

A formação do smog ocorre quando os $\mathrm{NO}_{\mathrm{X}}$, juntamente com os COV, reagem sob radiação da luz solar, propiciando a formação de gases agressivos, os chamados oxidantes fotoquímicos, onde o ozônio é o mais importante e abundante exemplo [11].

O smog é caracterizado como uma massa de ar estagnada (em virtude de uma inversão térmica) com vários gases, vapores e fumaça. Essencialmente, é o resultado da mistura de ozônio, nitrato de peroxiacetila, aldeídos e outros produtos da oxidação de hidrocarbonetos, aerossóis ácidos, óxidos de nitrogênio, etc. O smog promove na atmosfera redução de visibilidade, causa tosse, sensação de peito aberto, asma, irritação dos olhos e dor de cabeça, podendo até mesmo ocasionar a morte, caso o individuo permanecer em uma prolongada exposição nessa massa de ar [6,11,33].

\section{A UTILIZAÇÃO DE COMBUSTÍVEIS ALTERNATIVOS COMO FONTE DE ENERGIA MAIS LIMPA}

As fontes renováveis de energia têm sido a solução escolhida por diversos países, tanto para minimizar os problemas ambientais como para aumentar a segurança no suprimento de energia (diversidade da matriz energética), uma vez que estas podem, em muitos casos, substituir as fontes convencionais de origem fóssil [40].

É importante ressaltar que, diferentemente dos combustíveis fósseis, a queima de fontes renováveis, apesar de emitir quantidade significativa de $\mathrm{CO}_{2}$, apresenta a vantagem de promover a recaptura desse carbono por meio da fotossíntese, absorvendo $\mathrm{CO}_{2}$ da atmosfera, criando um ciclo fechado de absorção-liberação ("emissão zero") [41]. A literatura específica apresenta alguns trabalhos que abordam a utilização de combustíveis (madeira, metanol, etc.) como alternativa à utilização de combustíveis fósseis convencionais na questão "carbono-zero" [42-44].

O Brasil está entre os maiores produtores e consumidores de biodiesel do mundo. Segundo a Agência Nacional de Petróleo (ANP), a produção em 2008 foi de 1,2 bilhões de litros de biodiesel com capacidade de produção de 3,7 bilhões em 2009. O biodiesel pode ser produzido a partir de óleos vegetais (de espécies como dendê, girassol, soja, mamona, etc.) e gordura animal. Para que possa ser usado nos processo de combustão em motores, o óleo vegetal passa pelo processo de transesterificação com álcoois usando catálise ácida ou básica, produzindo glicerol puro como subproduto $[45,46]$.

Em 2003 foi criado o Programa Nacional de Produção e Uso do Biodiesel, mas vale ressaltar que há quase meio século o Brasil faz pesquisas sobre $o$ combustível, e se tornou pioneiro no processo de produção do óleo, que foi patenteado em 1980. Em 2005, com a Lei ${ }^{\circ}$ 11.097, estabeleceu a obrigatoriedade da adição de um percentual mínimo de $2 \%$ de biodiesel ao óleo diesel comercializado em qualquer parte do território nacional a partir de 2008 e de 5\% em 2013. Em 2009, o Conselho Nacional de Política Energética (CNPE), através da Resolução n. 02, de 27 de abril desse mesmo ano, estabeleceu em $4 \%$ o percentual mínimo obrigatório de adição de biodiesel ao óleo diesel (comercializado a partir do dia $1^{\circ}$ de julho). [47-49].

Com relação aos aspectos ambientais, quando comparados os combustíveis, diesel, biodiesel a $20 \%$ em mistura com diesel (B20), gás natural e biodiesel a $100 \%$ (B100), é fato que os maiores valores de emissões de poluentes (dióxido de carbono, monóxido de carbono, hidrocarbonetos, óxidos de enxofre, óxidos de nitrogênio, ozônio e material particulado) provêm do diesel e os menores do B100, persistindo também no B20, porém em menores proporções [50,51].

Desde 1975, com o lançamento do programa Proálcool (criado devido à turbulência no mercado internacional do petróleo e que tinha por objetivo substituir 
em larga escala os seus derivados), o Brasil se tornou pioneiro na produção de etanol produzido a partir da canade-açúcar. O etanol é definido quimicamente como um álcool incolor, volátil, inflamável e totalmente solúvel em água. O etanol brasileiro é o que mais reduz emissões de gases que provocam o efeito estufa, em pelo menos $80 \%$. Já os biocombustíveis produzidos a partir do milho nos Estados Unidos e à base de trigo em alguns países europeus, permitem reduções de apenas 20 a $50 \%$ e 30 a $60 \%$, respectivamente [52].

Ainda outro importante recurso renovável é a biomassa, abordada anteriormente, oriunda de matéria orgânica (de origem animal ou vegetal) que pode ser utilizada na produção de energia, depois de transformada pelos processos de pirólise, gaseificação, combustão e cocombustão. A viabilidade de uso cada vez maior da bioenergia vem sendo estudado em vários países. Baixo custo, disponibilidade e baixa emissão de poluentes são algumas das vantagens de sua implantação na matriz energética [53-58].

Em geral, uma das resistências alegadas com relação ao uso de combustíveis alternativos está no seu poder calorífico inferior (PCI), apontados por muitos como sendo menor em relação aos combustíveis convencionais, o que poderia conferir um menor rendimento da máquina. No entanto, alguns dados mais concretos podem desmistificar esse fato. Segundo parâmetros descritos pelo U.S. Department of Agriculture and U.S. Department of Energy [59], por exemplo, o biodiesel a 100\% apresenta PCI igual a $8,83 \mathrm{Kcal} \mathrm{g}^{-1}$ e o etanol 7,97 $\mathrm{Kcal} \mathrm{g}^{-1}$ contra 11,39 Kcal g ${ }^{-1}$ do diesel. Entretanto, como os biocombustíveis possuem oxigênio na sua molécula, o rendimento da combustão é maior, minimizando o consumo final de combustível [60, citado por 18]. Segundo Nicoll [61], o biodiesel com até $30 \%$ em mistura com diesel não prejudica a eficiência do combustível, por vezes até aumentando-a.

Um fato importante e que deve ser enfatizado é que a utilização de algumas alternativas renováveis exigem enormes extensões de terras, o que pode impor um certo limite à sua utilização, uma vez que seu cultivo poderia "estar prejudicando" o cultivo de culturas voltadas à alimentação. Grãos como soja, canola, dentre outros, antes destinados tão somente à alimentação, agora figuram como importantes matérias primas na produção de biocombustíveis o que, sem dúvida, acaba gerando controvérsia não apenas por parte de produtores rurais e indústrias do setor como entre lideranças políticas. Nesta última categoria, despontam basicamente duas correntes distintas: a primeira afirma que os biocombustíveis são os maiores responsáveis pela definição de preços das “commodities" agrícolas; além disso, a própria questão territorial é levantada, uma vez que propriedades de agricultura familiar já estariam em grande parte voltadas ao plantio de matérias primas para a fabricação de biocombustíveis. A segunda corrente (caso do governo brasileiro), ressalta que a produção de grãos voltada às indústrias de alimentos e biocombustíveis pode andar juntas. Mesmo entre diferentes organismos (como BIRD, Banco Mundial, ONU) não há consentimento em termos do impacto "alimentos versus combustíveis". Os próprios números apresentados por eles são muitas vezes divergentes, indicando diferentes percentuais em termos de responsabilidade por parte dos biocombustíveis na atual crise alimentar [62]. O certo é que muito ainda tem que ser avaliado em termos de impacto: se por um lado, de fato a produção de grãos-alimento concorre com a produção de grãos-combustível, por outro deve-se ter consciência da importância em se diversificar a matriz energética, por todas as implicações que a utilização do petróleo traz (nãorenovação desse recurso, poluição, etc.). De qualquer modo, ambas as situações podem conviver juntas, desde que evidentemente haja um equilíbrio em termos de produção e destinação desses grãos.

Enfim, os biocombustívies são aclamados por reduzir a dependência energética, aumentar a receita agrícola e principalmente ajudar a combater as alterações no clima. Além disso, a utilização dessas alternativas energéticas pode gerar, para as indústrias interessadas, a possibilidade de obtenção de créditos de carbono, sob a forma de projetos de Mecanismo de Desenvolvimento Limpo (MDL), o mecanismo de flexibilidade previsto no Protocolo de Quioto para ajudar os países do Anexo-I a alcançarem suas metas definidas de redução. Os créditos de carbono ou Redução Certificada de Emissões (RCE) podem ser negociados no mercado internacional (com os países do Anexo-I); são certificados emitidos quando ocorre a redução de emissão de gases do efeito estufa, onde um crédito de carbono equivale a uma tonelada de dióxido de carbono [63]. O Brasil ocupa atualmente o terceiro lugar em número de projetos em todo o mundo (cerca de 255 projetos), dos quais 66 possuem a certificação [64].

\section{CONCLUSÕES}

A dependência dos derivados do petróleo como fonte de energia pelas diferentes atividades antropogênicas gera uma série de emissões de poluentes que, de forma substancial, altera a qualidade da atmosfera. O excesso de emissões de monóxido de carbono, dióxido de carbono, óxidos de nitrogênio, óxidos de enxofre, compostos orgânicos voláteis e material particulado, não só provoca problemas à saúde do ser humano, mas também impactos ao meio ambiente, tanto de caráter local, como o "smog", como global, como o efeito estufa.

A questão da substituição energética deve ser pensada em termos globais, desde o seu cultivo ou extração até o seu destino final (análise do ciclo de vida do produto ACV). A menor emissão atmosférica durante o seu consumo, por exemplo, pode não justificar um maior impacto durante sua extração ou mesmo disposição final. Todos os tipos de energia impactam o meio ambiente em maior ou menor grau e em diferentes etapas do seu ciclo geração-consumo-disposição; o etanol, por exemplo, defendido como fonte mais saudável ao meio ambiente, está relacionado a queimadas antes da colheita, ou mesmo à utilização de máquinas movidas à diesel para transporte ou até mesmo para a colheita. A própria distribuição do etanol deve ser incluída no escopo da análise do seu ciclo de vida, já que a grande maioria de sua produção escoa por rodovias, 
uma opção bastante inconveniente do ponto de vista ambiental.

É importante destacar ainda que outros combustíveis, como o hidrogênio, são considerados ainda mais "saudáveis" que os apresentados anteriormente. Entretanto, encontram-se em fase de pesquisa (formas de obtenção e de aplicação) de modo que seu uso, em fontes fixas e móveis, ainda encontra-se bastante incipiente e restrito a alguns países.

\section{EVALUATION OF GASEOUS EMISSIONS FROM DIFFERENT FUELS APPLIED IN INDUSTRIES AND THEIR ENVIRONMENTAL IMPACTS}

ABSTRACT: This work reviews the main fuels used in industrial processes, emphasizing the gases from these emissions. The air pollution caused by these pollutants has a direct impact over the human health and ecosystems, due to liberation of these gases to the atmosphere at high rates. For several years, discussions about this theme deal the minimization of the environmental problems and international agreements have been done focusing on substitution of conventional fuels for another ones. The alternative energy resources has been chosen by their benefits.

Keywords: Air pollution, Biofuel, Gaseous emissions, Industry.

\section{AGRADECIMENTOS}

Os autores agradecem à Fundação Araucária do Paraná pelo auxílio financeiro dado ao projeto.

\section{REFERÊNCIAS}

[1] BRANCO, S. M.; MURGEL, E.; Poluição do ar; 2. ed.; Moderna: São Paulo, 2004. 112 p.

[2] KAWANO, M. Desenvolvimento, validação e aplicação de um modelo matemático para dispersão de poluentes atmosféricos. 2003. 109f. Dissertação (Pós graduação em Engenharia Ambiental - Mestrado) - Universidade Federal de Santa Catarina, Florianópolis. 2003.

[3] BRAUN, S.; APPEL, L. G.; SCHMAL, M. A poluição gerada por máquinas de combustão interna movidas à diesel - A questão dos particulados, estratégias atuais para redução e controle das emissões e tendências futuras. Scientific eletronic library online, 2003. Disponível em: < http://www.scielo.br/pdf/qn/v27n3/20176.pdf >. Acesso em 06/06/2008.

[4] GREENPEACE. Entenda mudanças climáticas. Disponível em: <http://p2raw.greenpeace.org/brasil/greenpeace-brasilclima/entenda/o-que-são>. Acesso em 19/08/2008.
[5] LORA, E. S.; Preservação e controle da poluição nos setores energéticos, industrial e de transporte; ANEEL: Brasília, 2000. 862p.

[6] BAIRD, C. Química ambiental; Tradução, Maria Angeles Lobo Recio e Luiz Carlos Marques Carrera. 2. ed.; Bookman: Porto Alegre, 2002. 622p.

[7] UNFCCC - UNITED NATIONS FRAMEWORK CONVENTION ON CLIMATE CHANGE. Protocolo de Quioto, 2a ed. Brasília: MCT, 001. 34p.

[8] IPCC. Climate change 2001: The Scientific Basis. A report of Working Group I of the Intergovernmental Panel on Climate Change. Bonn: IPCC, 2001.

[9] REIS, L. B.; FADIGAS, E. A. A.; CARVALHO, C. E.; Energia, recursos naturais e a prática do desenvolvimento sustentável; Manole: Barueri, 2005 (Coleção ambiental).

[10] MONTEIRO, K. V.; ORTIZ. L.; MARCUZZO, S. F.; FONSECA, J.; BARCELLOS, C.; SANTOS, T.; BACKES, P. Carvão: o combustível de ontem. Porto Alegre: Núcleo amigos da Terra Brasil, 2004. Disponível em: <www.natbrasil.org.br/Docs/carvao_ combustiveldeontem.pdf>. Acesso em 24/10/2008.

[11] ÁlVARES Jr., O. M.; LACAVA, C. I. V.; FERNANDES, P. S.; Tecnologias e gestão ambiental Emissões atmosféricas; Serviço Nacional de Aprendizagem Industrial (SENAI): Brasília, 2002. 373p.

[12] MASTRAL, A. M.; CALLÉN, M. S.; GARCIA, T. Toxic organic emissions from coal combustion. Fuel Processing technology, vol. 67, p. 1-10, 2000.

[13] ROSS, A. B.; JONES, J. M.; CHAIKLANGMUANG, S.; POURKSHANIAN, M. ; WILLIAMS, A. ; KUBICA, K.; ANDERSSON, J. T.; KERST, M.; DANIHELKA, P.; BARTLE, K. D. Measurement and prediction of the emission of pollutants from the combustion of coal and biomass in a fixed bed furnace. Fuel, vol. 81, p. 571-582, 2002.

[14] HU, Y.; NAITO, S.; KOBAYASHI, N.; HASATANI, M. $\mathrm{CO}_{2} \cdot \mathrm{NO}_{\mathrm{x}}$ and $\mathrm{SO}_{2}$ emissions from the combustion of coal with high oxygen concentration gases. Fuel, vol. 79, p. 1925-1932, 2000.

[15] ZHANG, H.; WANG, J. Combustion characteristics of a diesel engine operated with diesel and burning oil of biomass. Renewable Energy, vol. 31, p. 1025-1032, 2006.

[16] CHEN, H.; WANG, J.; SHUAI, S.; CHEN, W. Study of oxygenated biomass fuel blends on a diesel engine. Fuel, vol. 87 , p. 3462-3468, 2008.

[17] LOBKOV, D. D. Análise econômica para a substituição do uso de combustível diesel por GNC no transporte público de passageiros. 2005. 111f. Dissertação (Pós-graduação em 
Engenharia Civil - Mestrado) - Universidade Estadual de Campinas, Campinas. 2005.

[18] KOZERSKI, G. R.; HESS, S. C. Estimativa dos poluentes emitidos pelos ônibus e microônibus de Campo Grande/MS, empregando como combustível diesel, biodiesel ou gás natural. Scientific electronic library online, 2006. Disponível em: <http://www.scielo.br/pdf/esa/v11n2/30470.pdf>. Acesso em 28/05/2008.

[19] CARVALHO, M. L. O gás natural e a matriz de insumo produto. 2006. 89f. Dissertação (Pós-graduação em Engenharia Mecânica - Mestrado) - Universidade Estadual de Campinas, Campinas. 2006.

[20] PETROBRÁS. Espaço conhecer. Disponível em: <http://www2.petrobras.com.br/EspacoConhecer/>. Acesso em 23/09/2008.

[21] ANEEL - Agência Nacional de Energia Elétrica. Gás Natural. Disponível em: $<$ www.aneel.gov.br/aplicacoes/atlas/pdf/09-

Gas_Natural(2).pdf>. Acesso em 06/06/2008.

[22] CORTEZ, L. A. B.; LORA, E. E. S.; GÓMEZ, E. O.; Biomassa para energia; Editora da Unicamp: Campinas, 2008. 736p.

[23] BEN - Balanço Energetico Nacional. Balanço Energético Nacional 2008: Ano base 2007. EPE: Rio de Janeiro, 2008. 244p.

[24] BRIQUETES. Enbio - Energia de Biomassa. Dísponivel em: http://www.enbio.com.br/index.html>. Acesso em 18/02/2009.

[25] OPALC - Observatório de Políticas Públicas Ambientais da América Latina e Caribe. Siderurgia lidera ranking de indústrias poluidoras de São Paulo. Regido em: 24/04/2008. Disponível em: < http:// www.opalc.org.br/index2.php?option=com_content\&do_pdf $=1 \&=569>$. Acesso em 23/09/2008.

[26] CHIARANDA, H. S. Volatilização dos compostos BTEX em ambientes superficiais contaminados com gasolina e etanol: comparação entre concentrações medidas e simuladas. 2006. 119f. Dissertação (Pós-graduação em Engenharia Ambiental - Mestrado) - Universidade Federal de Santa Catarina, Florianópolis. 2006.

[27] CHU, H.; CHIOU, Y- Y.; HORNG, K-H.; TSENG, TK.; J. of Environ. Eng., Vol. 127, n. 05, p.438-447, 2001.

[28] GABAI, B. Remoção de compostos orgânicos voláteis (VOCs) por adsorção. 2000. 91f. Dissertação (Pósgraduação em Enga Hidráulica e Ambiental - Mestrado) Universidade Federal do Ceará, Fortaleza. 2000.
[29] LE COIREC, P.; Les composés organiques volatils dans l'environnement; Ecole de Mines de Nantes: Nates, 1998. $734 \mathrm{p}$.

[30] SCHIRMER, W. N. Avaliação do desempenho de nanotubos de carbono "cup-stacked" (CSCNT) na remoção de compostos orgânicos voláteis (COV) de correntes gasosas. 2007. 102f. Tese (Pós-graduação em Engenharia Ambiental - Doutorado) - Universidade Federal de Santa Catarina, Florianópolis. 2007.

[31] GHOSHAL, A. K.; MANJARE, S. D.; J. of Loss Prev. Proc. Ind., Vol. 15, p. 413-421, 2002.

[32] ZYSMAN, B.; SKELLY, P. D.; Metal Finishing, Vol. 98, n. 02., p.84-88, 2001.

[33] SCHIRMER, W. N. Amostragem, análise e proposta de tratamento de compostos orgânicos voláteis (COV) e odorantes em estação de despejos industriais de refinaria de petróleo. 2004. 140f. Dissertação (Pós-graduação em Engenharia Ambiental - Mestrado) - Universidade Federal de Santa Catarina, Florianópolis. 2004.

[34] RIBEIRO, H. E.; ASSUNÇÃO, J. V. Efeitos das queimadas à saúde humana. Scientific electronic library online, 2002. Disponível em: < http://www.scielo.br/pdf/ea/v16n44/v16n44a08.pdf>. Acesso em 22/09/2008.

[35] LISBOA, H. M. Controle da poluição atmosférica Cap. III: Efeitos da poluição atmosférica. Montreal: Primeira versão, 2007.

[36] WHO - World Health Organization. WHO strategy on air quality and health, cit., 2001.

[37] PHILIPPI Jr, A.; BRUNA, G. C.; ROMÉRO, M. A.; Curso de gestão ambiental. Manole: São Paulo, 2004 (Coleção ambiental).

[38] RITTL, C.; BELMONTE, R. V.; LEONARDI, G.; MICHELOTTI, G.; DONATTI, C.; FURTADO, M.; BODAS, C. Mudança do clima, Mudanças de vida - Como o aquecimento global já afeta o Brasil.: Greenpeace, 2006. Disponível em: <www.greenpeace.org.br/clima/pdf/cartilha_clima.pdf >. Acesso em 11/09/2008.

[39] IPCC - Intergovernmental Panel on Climate Change. Climate Change 2007: The Physical Science Basis. Contribution of Working Group I to the Fourth Assessment Report of the Intergovernamental Panel on Climate Change.

[40] SANTOS, M. A. Inserção do biodiesel na matriz energética brasileira: Aspectos técnicos e ambientais relacionados ao seu uso em motores de combustão. 2007. 116f. Dissertação (Pós Graduação em Energia - Mestrado) Universidade de São Paulo, São Paulo. 2007. 
[41] CARTILHA BIODIESEL. Vantagens na utilização do biodiesel. Disponível em: < www.biodieselbr.com/pdf/biodiesel/manual-biodiesel.pdf $>$. Acesso em 09/12/2008.

[42] CANNELL, M. G. R. Carbon sequestration and biomass energy offset: theoretical, potential and achievable capacities globally, in Europe and UK. Biomass and bioenergy, Vol, 24, p. 97-116, 2003.

[43] WEIMER, T.; SCHABER, K.; SPECHT, M.; BANDI, A. Methanol from atmospheric carbon dioxide: a liquid zero emission fuel for the future. Energy conversion and management, vol. 37, n. 6-8, p. 1351-1356, 1996.

[44] McFARLANE, D. W. Potential availability of urban wood biomass in Michigan: implications for energy production, carbon sequestration and sustainable forest management in the USA. Biomass and energy, vol. 33, p. 628-634, 2009.

[45] ANP - Agência Nacional de Petróleo. Biodiesel - O biodiesel obrigatório. Disponível em: <http://www.anp.gov.br/biocombustiveis/biodiesel.asp>. Acesso em 04/08/2009

[46] MIRANDA, G. R. Avaliação das emissões atmosféricas provenientes da combustão de diesel, biodiesel de resíduos de óleo de fritura e suas misturas. 2007. 108f. Dissertação (Pós-graduação em Engenharia Ambiental - Mestrado) Universidade Federal de Santa Catarina, Florianópolis. 2007.

[47] BIODIESEL BRASIL. O que é biodiesel?. Disponível em: <http://www.biodieselbr.com/biodiesel/biodiesel.htm>. Acesso em 20/02/2009.

[48] PORTAL DO BIODIESEL. O programa. Disponivel em: <http://www.biodiesel.gov.br/>. Acesso em 20/02/2009.

[49] ANP - Agência Nacional de Petróleo. Disponível em: $<$ http://www.anp.gov.br/conheca /noticias int.asp?int CodNoticia $=338$ > . Acesso em 04/08/2009b

[50] SIQUEIRA, M. R. D.; PAES, R. P.; FIGUEIREDO, G. S.; LESMO, R. F.; SATO, M. C. S.; Estimativa dos poluentes emitidos pelos ônibus e microônibus de Cuiabá e Várzea Grande - MT, empregando como combustível diesel, biodiesel ou gás natural. In: CONGRESSO BRASILEIRO DE ENGENHARIA SANITÁRIA E AMBIENTAL, 24, 2007, Anais... Belo Horizonte: ABES, 2007. CD-ROm.

[51] KUCEK, K. T.; DOMINGOS, A. K.; WILHELM, H. M.; RAMOS, L. P. 2004.; Considerações sobre o uso do biodiesel como modelo para projetos MDL. In: SANQUETA, C. R., BALBINOT, R., ZILIOTTO, M. A. B.; Fixação de carbono: atualidades, projetos e pesquisas; Ed. UFPR: Curitiba, p.183 - 195.
[52] FERNANDES, D. Etanol brasileiro é o que mais reduz emissões, diz OCDE. Revista Fator Brasil, Julho de 2008. Disponível em:

http://www.revistafatorbrasil.com.br/ver_noticia.php?not=4 6485>. Acesso em 01/02/2009.

[53] SAMANIEGO, M. R. P. uso de biocombustível da pirólise rápida da palha de cana em um motor de ciclo Otto. 2007. 117f. Dissertação (Pós-graduação em Engenharia Mecânica - Mestrado) - Universidade Estadual de Campinas, Campinas. 2004.

[54] JOHANSSON; J.; LUNDQVIST, U. Estimating Swedish biomass energy supply. Biomass and Bioenergy, vol. 17, p. 85-93, 1999.

[55] BOMAN, U. R.; TURNBULL, J. H. Integrated biomass energy systems and emissions of carbon dioxide. Biomass and bioenergy, vol. 13, p. 333-343, 1997.

[56] SAJJAKULNUKIT, B.; VERAPONG, P. Sustainable biomass production for energy in Thailand. Biomass and Bioenergy, vol. 25, p. 557-570, 2003.

[57] LEWANDOWSKI, I.; WEGER, J.; HOOIJDONK, A.; HAVLICKOVA, K.; DAM, J.; FAAIJ, A. The potential biomass for energy production in the Czech Republic. Biomass and Bioenergy, vol. 30, p. 405-421, 2006.

[58] PERERA, K. K. C. K.; RATHNASIRI, P. G.; SUGHATAPALA, A. G. T. Sustainable biomass production for energy in Sri Lanka. Biomass and Bioenergy, vol. 25, p. 541-556, 2003.

[59] U.S. DEPARTMENT OF AGRICULTURE AND U.S. DEPARTMENT OF ENERGY; 1998. Life cycle inventory of biodiesel and petroleum diesel for use in an urban bus. Final Report. 1998. Disponível em: http://www.nrel.gov/docs/legosti/fy98/24089.pdf.. Acessado em 16/12/2008.

[60] LAURINDO, J. C.; BUSSYGUIN, G. Estudo preliminar comparativo entre os combustíveis óleo diesel e éster metílico de óleo de soja. In: CONGRESSO BRASILALEMANHA SOBRE ENERGIAS RENOVÁVEIS E RECURSOS HÍDRICOS, 1999, Anais,... Fortaleza: GTZ, 1999.

[61] NICOLL, M. Fundação de Apoio à Pesquisa do Estado do Rio de Janeiro. O ar que o carioca respira é objeto de estudo apoiado pela FAPERJ. Regido em: 25/08/2005. Disponível em: <http://www.faperj.br/boletim_interna.phtml?obj_id=2329> Acessado em 18/12/2008.

[62] VLAHOU, A. Crise alimentar "não tem vilões nem mocinhos”, dizem especialistas. São Paulo, 05 set 2008. Disponível em: http://www1.folha.uol.com.br/folha/bbc/ult272u409023.sht

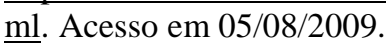


[63] REVISTA DA MADEIRA. Fonte limpa de energia. $n^{\circ}$ 114, Junho de 2008a. Disponível em: <http://www.remade.com.br/br/revistadamadeira.php>. Acesso em 10/01/2009.

[64] REVISTA DA MADEIRA. Mercado de carbono estimula setor florestal. $\mathrm{n}^{\circ} 112$, Abril de 2008b. Disponível em: <http://www.remade.com.br/br/revistadamadeira.php>. Acesso em 10/01/2009. 